\title{
ГИДРОФИЗИКА. ГИДРОГЕОЛОГИЯ
}

\section{ТЕПЛОВОЙ РЕЖИМ МЕЛКОВОДНОГО ОЗЕРА ЗИМОЙ}

\author{
Г. Э. Здоровеннова, Р. Э. Здоровеннов, Н. И. Пальшин, \\ Т. В. Ефремова, Г. Г. Гавриленко, С. Р. Богданов, А. Ю. Тержевик
}

Институт водных проблем Севера Карельского научного центра РАН

\begin{abstract}
Анализ данных полевых измерений температуры в небольшом мелководном озере Вендюрском в зимние месяцы 2014-2015 гг. с использованием высокочувствительного оборудования позволил выявить особенности теплового режима его водной толщи и придонного слоя. Оценки теплового потока, направленного из донных отложений в воду, показали резкое уменьшение его величины от 2-5 ВТ·м ${ }^{-2}$ в предледоставный период до $1-1,5$ Вт·м ${ }^{-2}$ в первые дни ледостава и затем плавное уменьшение до 0,4 Вт·м ${ }^{-2}$ к концу зимы. На фоне сезонного повышения температуры наблюдались ее пульсации $\Delta T$, которые изменялись во времени и по глубине в довольно широком диапазоне, при этом участки с «фоновыми» значениями на уровне в несколько тысячных градуса чередовались с «активными» интервалами, где величина $\Delta T$ возрастала на порядок и более. В придонных слоях наиболее резкие изменения температуры приводили к усилению теплопотока от фоновых значений 0,5-1,1 Вт·м ${ }^{-2}$ до 3-5 Вт·м ${ }^{-2}$. «Фоновым» колебаниям температуры соответствовали вертикальные перемещения изотерм порядка 1-2 мм и вертикальные скорости порядка $10^{-5} \mathrm{M} \cdot \mathrm{c}^{-1}$, «активным» - перемещения до нескольких см и скорости на один-два порядка выше. «Активные» интервалы наблюдались на фоне усиления атмосферного воздействия на озеро (резких перепадов атмосферного давления и усилений ветра). Значительные колебания глубины залегания изотерм и характер зависимости амплитуды колебаний температуры от глубины позволяют предположить их бароклинную природу, то есть они могут быть обусловлены внутренними волнами в стратифицированном озере.
\end{abstract}

Ключе в ы е сл о ва: температура воды; мелководное озеро; колебания; период ледостава; теплопоток.

G. E. Zdorovennova, R. E. Zdorovennov, N. I. Palshin, T. V. Efremova, G. G. Gavrilenko, S. R. Bogdanov, A. Yu. Terzhevik. THERMAL REGIME OF A SHALLOW LAKE IN WINTER

The thermodynamics of the water column and the bottom layer of a small shallow lake Vendyurskoe were identified from the analysis of temperature measurements by high resolution equipment during the winter 2014-2015. Estimates of the heat flux from the bot- 
tom sediments into the water revealed a sharp decrease in its value from $2-5 \mathrm{~W} \cdot \mathrm{m}^{-2}$ before lake freezing up to $1-1.5 \mathrm{~W} \cdot \mathrm{m}^{-2}$ in the first days of the ice-covered period, and then a slow decrease to $0.4 \mathrm{~W} \cdot \mathrm{m}^{-2}$ by the end of the winter. Temperature oscillations of different amplitudes and periods are observed against the background of its seasonal increase. The oscillations $\Delta T$ varied with time and depth in a wide range, with areas of "background" values of a few thousandths of a degree alternating with "active" intervals where $\Delta T$ value increased by an order of magnitude or more. The sharpest changes in near-bottom temperature led to an increase in the heat flux from the background values of $0.5-1.1 \mathrm{~W} \cdot \mathrm{m}^{-2}$ to 3-5 W. $\mathrm{m}^{-2}$. "Background" temperature oscillations corresponded to 1-2 mm vertical displacement of the isotherms, and vertical rates of about $10^{-5} \mathrm{~m} \cdot \mathrm{s}^{-1}$, whereas "active" oscillations corresponded to displacements of up to several $\mathrm{cm}$ and rates 1-2 orders of magnitude higher. "Active" intervals were observed when atmospheric forcing on the lake (sharp fluctuations of atmospheric pressure and wind intensification) increased. Significant fluctuations of the depth of isotherms and the dependence of the temperature oscillation amplitude on the depth suggest they are of baroclinic nature, i. e. may be caused by internal waves in a stratified lake.

Keywords: water temperature; shallow lake; fluctuations; ice-covered period; heat flux.

\section{Введение}

В последнее время усилился интерес к исследованиям сезонно замерзающих озер, однако многие процессы и явления, происходящие в них, остаются недостаточно изученными. На малых бореальных озерах ледостав продолжается несколько месяцев [Kirillin et al., 2012], оказывая определяющее влияние на функционирование их экосистем. Зимой гидрофизические процессы в озерах замедлены. В условиях изолированности от ветрового воздействия подледные течения и циркуляции играют решающую роль в перераспределении тепла, солей, газов, растворенных и взвешенных веществ по водной толще озер, несмотря на то, что их скорости не превышают нескольких мм· ${ }^{-1}$ [Петров и др., 2007; Rizk et al., 2014]. Наиболее заметные изменения температуры мелководных озер происходят в течение первого месяца подледного периода [Петров и др., 2006], причем особенно выражены в придонном слое. Тепловой поток, направленный из донных отложений в воду и максимальный в первые недели ледостава, постепенно истощается. По оценкам, на разнотипных бореальных озерах величина теплопотока, направленного из донных отложений в воду, в начале зимы достигает 10 Вт·м ${ }^{-2}$, к концу первого месяца ледостава снижается до 1-2 Вт.м ${ }^{-2}$ и затем продолжает незначительно уменьшаться [Bengtsson, Svensson, 1996; Kirillin et al., 2009; Zdorovennova, 2009; Гавриленко и др., 2015]. Атмосферное воздействие на покрытое льдом озеро традиционно рассматривается лишь с точки зрения изменения толщины льда и формирования его структуры [Бояринов, Петров, 1991]. В работе [Malm et al., 1997] высказано предположение, что перепады атмосферного давления и интенсификация ветра над озером могут приводить к усилению подледной гидродинамики: синхронные измерения колебаний поверхности льда, скорости ветра, перепадов атмосферного давления над озером и скорости течения подо льдом показали, что при усилении атмосферного воздействия происходит интенсификация течений. В работе [Здоровеннов и др., 2011] отмечено полное затухание осциллирующих колебаний температуры в штилевых условиях. Однако весь спектр атмосферного воздействия на малое озеро, покрытое льдом, и физические механизмы тепломассопереноса, происходящие как в его водной толще, так и в придонных слоях, остаются слабоизученными.

Настоящая работа посвящена изучению особенностей теплового режима покрытого льдом озера. Приведены результаты измерений температуры воды в небольшом карельском озере Вендюрском в зимние месяцы 2014-2015 гг. и рассмотрены особенности термического режима его водной толщи и придонного слоя в течение зимнего сезона.

\section{Материалы и методы}

Объект исследования - небольшое мелководное мезотрофное озеро Вендюрское, расположенное в южной части Карелии $\left(62^{\circ} 10^{\prime}-62^{\circ} 20^{\prime} \mathrm{N}, \quad 33^{\circ} 10^{\prime}-33^{\circ} 20^{\prime} \mathrm{E}\right)$. Площадь зеркала озера оценивается в 10,4 км², объем вод $\sim 5,5 \cdot 10^{7} \mathrm{M}^{3}$, средняя глубина составляет 5,3 м, максимальная - 13,4 м; площадь водосборного бассейна - 82,8 км². В озеро впадает р. Риндозерка и несколько небольших ручьев, вытекает р. Кулапдеги, однако объем их стока невелик. Сток с водосбора озера 
и атмосферные осадки оказывают определяющее влияние на изменения объема озерных вод в течение года. Коэффициент водообмена озера равен 0,4 год-1. Прозрачность воды по диску Секки достигает 3,0 0 0,5 м. Донные отложения представляют собой песок на мелководье (на глубинах не более 2-3 м) и коричневые и темно-коричневые илы в глубоководной части озера [Литинская, Поляков, 1975].

В период с октября 2014 г. по июнь 2015 г. в центральной глубоководной части озера Вендюрского на глубине 11,1-11,3 м проводились измерения температуры водной толщи и придонного слоя воды с высоким разрешением по пространству и времени. Высокочувствительные датчики температуры производства канадской фирмы «RBR Ltd» (точность $\pm 0.002^{\circ} \mathrm{C}$, раз решение $\left.<0.00005^{\circ} \mathrm{C}\right)$, были размещены на косе и придонной платформе [Патент..., 2015]. На косе использовалось 16 датчиков; в придонном слое датчики располагались через 2-30 см, в водной толще - через метр. Датчики находились на глубинах 2,34; 2,84; 3,34; 3,84; 4,84; 6,84; 7,84; 8,84; 9,84; 10,34; 10,59; 10,89; 10,94; 10,$99 ; 11,01$ и 11,03 м. На придонной платформе десять датчиков размещались со сдвигом 2 см. Придонная платформа погрузилась в ил, верхний горизонт наблюдений располагался на глубине около 2 см в донных отложениях, нижний - на глубине около 20 см. Дискретность измерений на термокосе и придонной платформе составляла одну минуту. Данные обрабатывались с использованием пакетов Excel и SciLab. Тепловой поток $Q$ из донных отложений в воду был оценен по градиентному методу:

$$
Q=-\lambda \frac{d T}{d z}
$$

где $\lambda$ - коэффициент молекулярной теплопроводности, для воды принималось значение 0,56 Вт. $\mathrm{M}^{-1}{ }^{\circ} \mathrm{C}^{-1}$, для донных отложений 0,62 Вт. $\mathrm{M}^{-1}{ }^{\circ} \mathrm{C}^{-1}$ [Malm et al., 1997], $d T / d z$ - вертикальный градиент температуры, ${ }^{\circ} \mathrm{C} \cdot \mathrm{M}^{-1}$, между соседними датчиками.

Эффективный коэффициент температуропроводности $\lambda_{\text {eff }}$ был оценен по соотношению между линейным масштабом деформации температурного профиля и временем этой деформации [Golosov et al., 2003]:

$$
\lambda_{\text {eff }}=\frac{(D-h)^{2}}{t}
$$

где $D$ - глубина, м; $h$ - толщина перемешанного слоя, м; $t$ - время, с.

Вертикальные смещения $s$ и скорости вертикальных смещений $V_{z}$ в условиях устойчивой стратификации рассчитывались по амплитуде пульсаций температуры $\Delta T$ и градиенту средней температуры $\bar{T}$ :

$$
\begin{gathered}
s=\Delta T /(d \bar{T} / d z) \\
V_{z}=s / \Delta t
\end{gathered}
$$

В анализе погодных условий района исследований использовались данные по одной из наиболее близко расположенных к оз. Вендюрскому (расстояние порядка 70 км) метеостанций Федеральной службы РФ по гидрометеорологии и мониторингу природной среды - MC «Петрозаводск» (WMO_ID=22820, информация получена на сайте «Расписание погоды», rp5.ru).

\section{Результаты и обсуждение}

Сплошной ледяной покров образовался на озере Вендюрском 21 ноября 2014 г. при средней температуре воды по вертикали в центральной части озера около $0,05^{\circ} \mathrm{C}$. Сразу после появления льда началось резкое повышение температуры воды, наиболее выраженное в придонном слое центральной котловины (рис. 1, А). Уже к 30 ноября, через девять суток ледостава, температура воды вблизи границы с донными отложениями повысилась до $2{ }^{\circ} \mathrm{C}$, при этом температура верхнего пятиметрового слоя водной толщи увеличилась всего на $0,05^{\circ} \mathrm{C}$ (рис. 1, Б). Температура верхнего слоя донных отложений в центральной глубоководной части озера к концу первого месяца ледостава достигла $3,5^{\circ} \mathrm{C}$, затем продолжала повышаться и к концу зимы превышала $4,5^{\circ} \mathrm{C}$ (рис. 2, A).

Теплопоток, направленный из донных отложений в воду, в центральной части озера достигал в предледоставный период 2,54,5 Вт.м ${ }^{-2}$, после появления сплошного льда резко снизился до 1-1,5 Вт·м ${ }^{-2}$, затем в течение зимы продолжал понижаться и в конце ледостава не превышал 0,4 Вт.м ${ }^{-2}$ (рис. 2, Б).

Очевидно, что резкое повышение температуры воды придонных слоев в первые дни и недели ледостава не могло быть достигнуто только посредством молекулярной теплопередачи. Оценки коэффициента эффективной температуропроводности, выполненные по деформации вертикального температурного профиля в центральной части озера Вендюрского в течение первой недели ледостава 21-28 ноября 2014 г. (формула 1), показали значение $6,6 \cdot 10^{-5} \mathrm{M}^{2} \cdot \mathrm{c}^{-1}$, что превышает молекулярный уровень на два порядка. Эти значения хорошо согласуются с оценками $\lambda_{\text {eff, }}$ полученными ранее по данным измерений температуры 

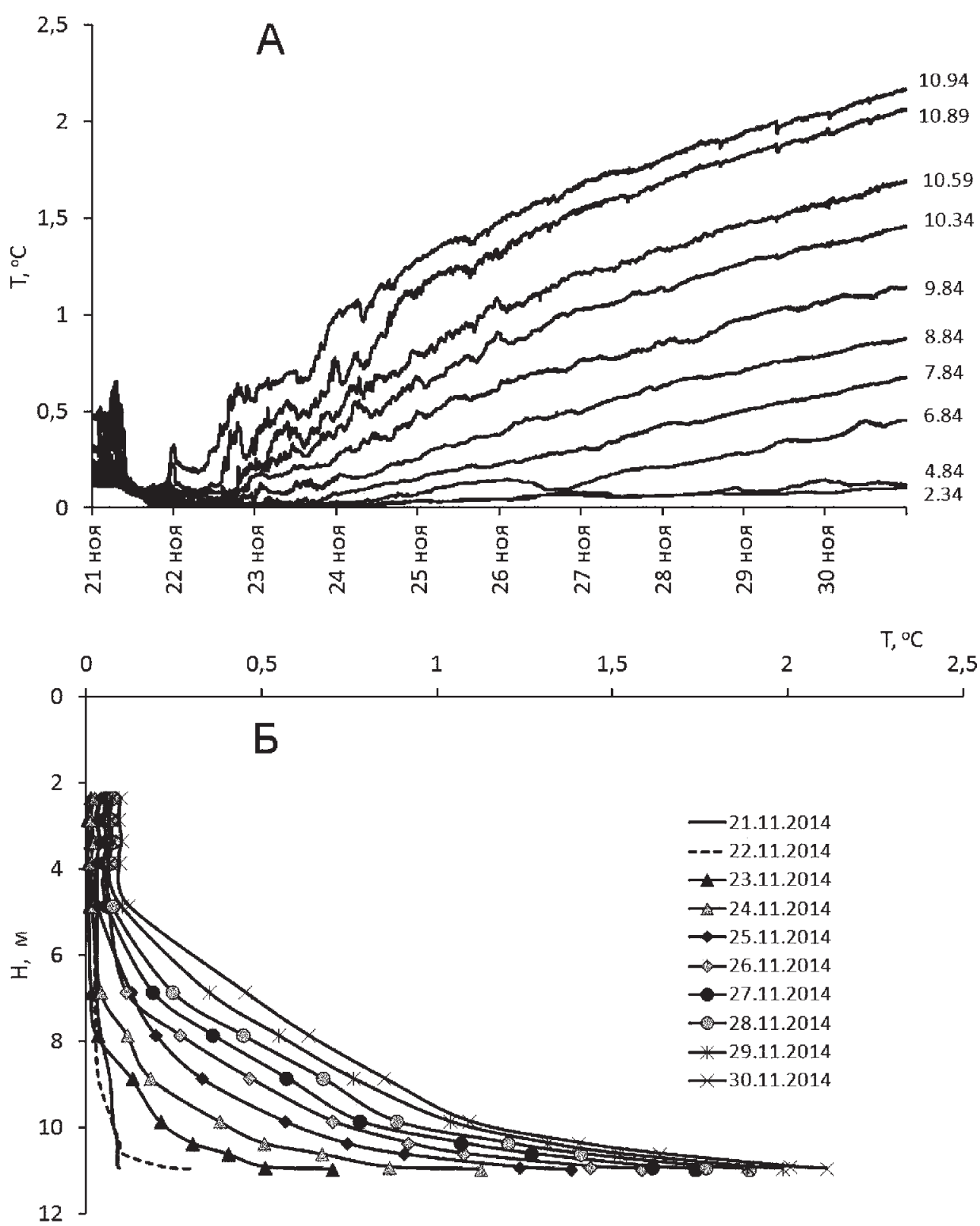

Рис. 1. А - температура водной толщи оз. Вендюрского 21-30 ноября 2014 г. Цифрами обозначена глубина горизонта измерений, м. Б - вертикальные профили температуры воды 21-30 ноября 2014 г.

в озере Вендюрском в 1995-1997 и 19982000 гг. для первых четырех недель ледостава от $1 \cdot 10^{-4}$ до $8,5 \cdot 10^{-6} \mathrm{M}^{2} \cdot \mathrm{c}^{-1}$, со средним значени-

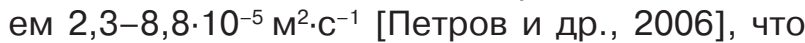
позволяет с уверенностью говорить о том, что теплоперенос в придонных слоях озера в начальный период зимы не ограничивается только молекулярной диффузией.

Определенный вклад в повышение температуры придонных слоев центральной котловины может вносить склоновый перенос теплых вод с мелководий. Механизм этого переноса описан в ряде работ [Mortimer, Mackereth, 1958; Malm, 1998]. Оценки изменения теплосодержания столба воды по разнице тепловых потоков на границах с донными отложениями и льдом проводились по данным последовательных пространственных температурных съемок на озере Вендюрском в зимний сезон 1995-1996 гг.

Было показано, что на мелководьях (с глубиной менее 3-4 м) теплосодержание столба воды уменьшается в течение зимнего сезона, а в глубоководных частях акватории - увеличивается, причем эти изменения лишь частично покрываются разницей тепловых потоков, что позволяет предполагать наличие горизонтального переноса тепла в озере.

Другим очевидным объяснением наблюдающейся изменчивости температурного профиля 

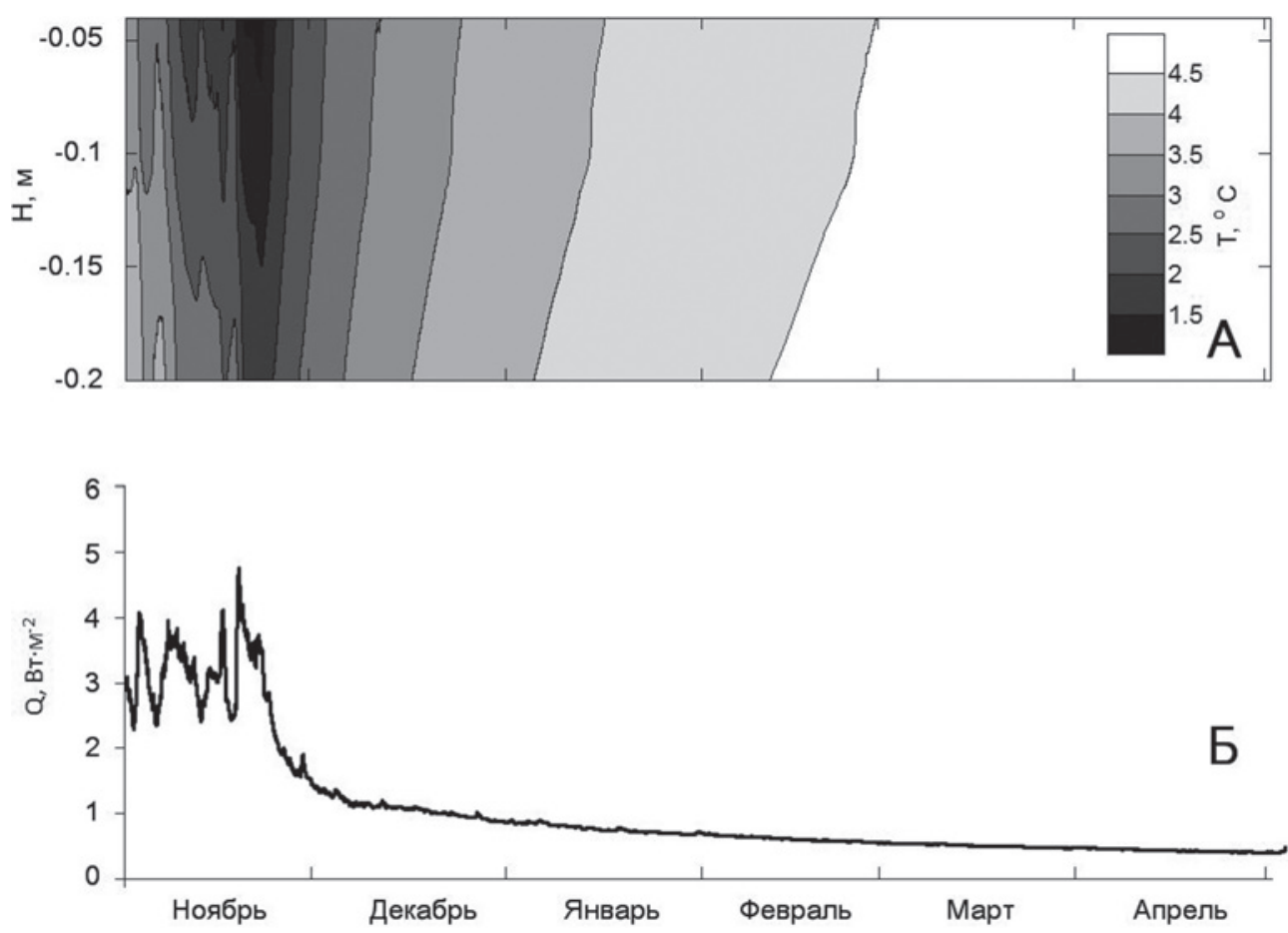

Рис. 2. Температура верхнего 20-см слоя донных отложений оз. Вендюрского (А) и теплопоток на глубине 10 см под поверхностью донных отложений (Б) в период с 1 ноября 2014 г. по 30 апреля 2015 г.

в начальный период зимы может быть усиление теплового потока, направленного из донных отложений в воду при интенсификации подледной гидродинамики в целом и придонных слоев в частности.

В записях температурных датчиков косы на фоне сезонного роста температуры отмечались флуктуации разной периодичности и амплитуды (рис. 3, А). В частности, амплитуда колебаний температуры достигала 0,010,5 ${ }^{\circ} \mathrm{C}$; периоды изменялись от 5-25 минут до нескольких часов. Как было показано ранее [Петров и др., 2006; Zdorovennova, 2009; Здоровеннов и др., 2011], на протяжении всей зимы в озере Вендюрском отмечаются колебания температуры воды и верхнего слоя донных отложений (достигающие десятых долей градуса), причем диапазон периодов этих колебаний весьма широк - от минут до нескольких суток. Основной причиной таких колебаний были названы баротропные и бароклинные сейши.

Наряду с осциллирующими изменениями, наиболее часто встречающимися в записях температурных датчиков, зимой 2014-2015 гг. наблюдалась и менее упорядоченная динамика. В частности, в придонных слоях центральной котловины часто происходили резкие всплески температуры, «эпицентр» которых обычно находился в воде на некотором расстоянии (порядка 20 см) от границы с донными отложениями.
В качестве примера на рис. 3 приведено одно из таких «событий», зафиксированное датчиками термокосы в период с 12 ч 18 января до 19 ч 19 января 2015 г. На расстоянии 0,070,21 м над дном наблюдалось резкое падение температуры в 12 ч 18 января и в 7 ч 19 января. Затем температура скачкообразно изменялась, то понижаясь на $0,05-0,3^{\circ} \mathrm{C}$ за 5-10 минут, то повышаясь. На горизонте 0,51 м изменения температуры были сглажены: уменьшение температуры в течение 6-7 ч на 0,2 ${ }^{\circ} \mathrm{C}$, затем температура менялась мало до 6 ч утра 19 января, когда началось повышение температуры до фоновых значений, продолжавшееся 4 ч. На вышележащих горизонтах, расположенных над дном в 1,26 и 2,26 м, были зафиксированы кратковременные резкие повышения температуры на $0,1-0,2^{\circ} \mathrm{C}$ в течение нескольких минут и возвращение к фоновым значениям. Наиболее выраженные изменения температуры были зафиксированы на горизонтах 0,16-0,51 м. Изменения температуры вызывали резкие возрастания теплопотока от фоновых значений 0,7-1,1 Вт.м ${ }^{-2}$ до 3-5 Вт.м ${ }^{-2}$ (рис. 3, Б). Максимальная величина теплопотока соответствовала горизонтам с максимальными температурными градиентами. Резкие скачки температуры наблюдались более 10 раз в течение зимы 2014-2015 г. В предыдущие годы исследований описанные резкие скачки температуры в придонных слоях глубоководной 

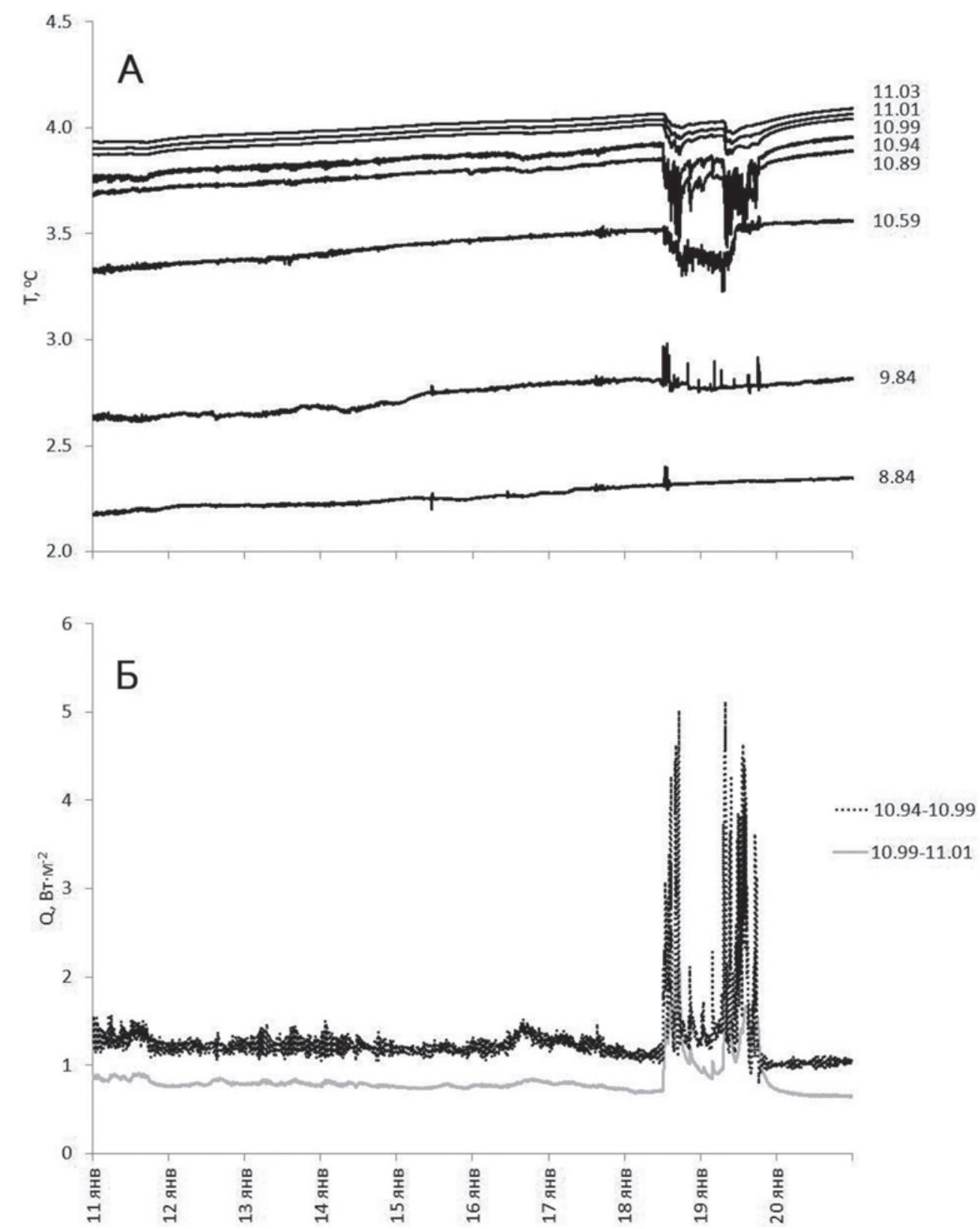

Рис. 3. Температура придонных слоев центральной глубоководной котловины оз. Вендюрского (А) и теплопоток в придонных слоях воды (Б) в период с 11 по 20 января 2015 г. Цифрами указаны глубины, м. Данные термокосы

котловины также фиксировались неоднократно за сезон.

Пульсации температуры в рамках стандартных приближений можно рассматривать как индикатор перемещений слоев жидкости по вертикали. Анализ данных показал, что амплитуды пульсаций температуры изменяются во времени и по глубине в довольно широком диапазоне, при этом участки с «фоновыми» значениями на уровне в несколько тысячных градуса чередуются с интервалами, где величина $\Delta T$ возрастает на порядок и более (рис. 4, A). Было обнаружено, что значения $\Delta T$ в придонных слоях, как правило, сопоставимы со значениями, характерными для основной толщи (рис. 4, А).

Расчеты вертикальных смещений и вертикальных скоростей по формулам 2 и 3 показали, что «фоновым» колебаниям температуры соответствовали вертикальные перемещения изотерм порядка одного миллиметра (рис. 4, Б) и вертикальных скоростей порядка $10^{-5}$ м· $\mathrm{c}^{-1}$ (рис. 4, В) - значения, вполне характерные для баротропной сейши и согласующиеся с зарегистрированными амплитудами колебаний льда (также порядка 1-2 мм), приведенными в работе [Malm et al., 1997]. В то же 

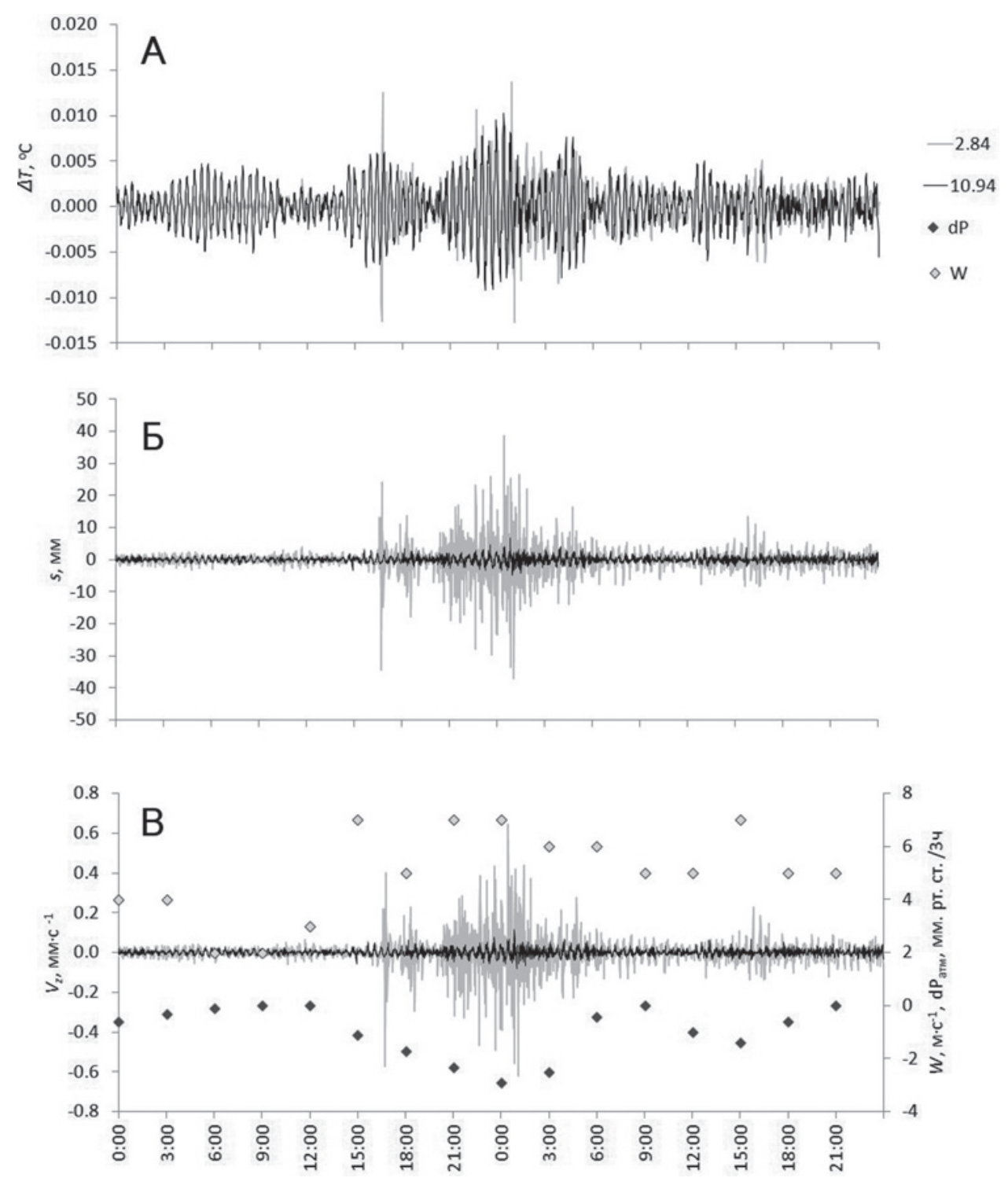

Рис. 4. Пульсации температуры воды (А), вертикальных смещений (Б) и вертикальной скорости (В) в поверхностном (2,84 м) и придонном (10,94 м) слоях водной толщи оз. Вендюрского 7-8 марта 2015 г. Цифрами указана глубина измерений, м. Данные термокосы. Скорость ветра $(W)$ и барическая тенденция $\left(\mathrm{dP}_{\text {атм }}\right)$ по ГMC Петрозаводск

время «активным» интервалам с повышенной амплитудой пульсаций температуры соответствовали вертикальные перемещения вплоть до нескольких сантиметров, а в отдельных случаях - и более 10 см. Такие вертикальные перемещения как минимум на порядок превышают возможные значения в случае баротропной сейши. Вертикальные скорости на активных интервалах увеличивались на 1-2 порядка.

Интересно, что усиление пульсаций температуры, а следовательно, и вертикальных смещений и вертикальных скоростей происходило на фоне резких перепадов атмосферного давления и усилений ветра. В частности, приведенному на рис. 4 случаю соответствовало усиление скорости ветра до 7-8 м· $\mathrm{c}^{-1}$ с порывами до $16 \mathrm{M} \cdot \mathrm{c}^{-1}$ и резкое падение атмосферного давления - на 2-3 мм рт. ст. за 3 ч в период с 15 ч 7 марта 2015 г. до 6 ч утра 8 марта 2015 г. (рис. 4, В). В течение зимы 2014-2015 гг. неоднократно отмечалось возрастание амплитуд пульсаций температуры, а следовательно, и вертикальных смещений и вертикальных скоростей, наиболее выраженное в поверхностных слоях водной толщи. Такие усиления происходили на фоне резких изменений погоды - при

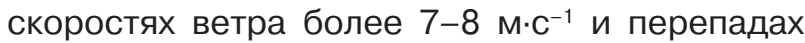
атмосферного давления порядка 2-3 мм рт. ст. за 3 ч. При уменьшении скорости ветра высокочастотная изменчивость температуры в течение нескольких часов снижалась до «фоновых» значений. 
В целом значительные колебания глубины залегания изотерм и характер зависимости амплитуды этих колебаний от вертикальной координаты позволяют предположить, что колебания в основном имеют бароклинную, а не баротропную природу, то есть могут быть обусловлены внутренними волнами в стратифицированном озере. До недавнего времени экспериментально подтвердить или опровергнуть существование внутренних волн не представлялось возможным в связи с отсутствием необходимых приборов. Однако с появлением высокочувствительного измерителя течений такая возможность у исследовательской группы появилась. И в ближайшем будущем планируется проведение синхронных измерений температуры воды и скоростей течения в покрытых льдом озерах, что позволит экспериментально проверить высказанное предположение.

\section{Заключение}

Анализ данных измерений температурь в небольшом мелководном озере Вендюрском позволил выявить новые особенности его теплового режима в зимний период. Характер изменения температурного профиля в первые дни ледостава и выполненные оценки эффективного коэффициента температуропроводности позволяют предполагать немолекулярный характер теплопереноса. В течение зимнего сезона в водной толще от поверхностных до придонных слоев присутствовали колебания температуры широкого диапазона амплитуд и периодов. Анализ пульсаций температуры, а также оценки вертикальных смещений и вертикальных скоростей позволили обнаружить ряд особенностей, совершенно не характерных для баротропных сейш, в частности, зависимость колебаний от глубины. Показано, что атмосферное воздействие на озеро может приводить к усилению подледной гидродинамики и ускорению тепломассообмена.

В целом приведенные оценки позволяют сделать вывод о том, что процессы теплопереноса в покрытом льдом озере могут определяться мелкомасштабными пульсациями и в той или иной степени обусловлены турбулентной теплопроводностью. Предположительно, обрушение или взаимодействие внутренних волн, их неустойчивость как раз и могут служить причиной возникновения мелкомасштабной перемежающейся турбулентности, ускоряющей теплообмен в покрытом льдом озере.

\section{Литература}

Бояринов П. М., Петров М. П. Процессы формирования термического режима глубоких пресноводных водоемов. Л.: Наука, 1991. 175 с.

Гавриленко Г. Г., Здоровеннова Г. Э., Здоровеннов Р. Э. и др. Теплопоток на границе вода-донные отложения в небольшом озере // Труды КарНЦ РАН. 2015. № 9, С. 3-9.

Здоровеннов Р. Э., Здоровеннова Г. Э., Пальшин Н. И., Тержевик А. Ю. Изменчивость термического и кислородного режимов мелководного озера зимой // Тр. КарНЦ РАН. 2011. № 4. С. 57-63.

Литинская К. Д., Поляков Ю. К. Озера Вендюрской группы - Урос, Риндозеро, Вендюрское // Водные ресурсы Карелии и их использование. Петрозаводск: Карельский филиал АН СССР, 1975. С. 57-66.

Патент РФ № 153787 7.07.2015.

Петров М. П., Тержевик А. Ю., Здоровеннов Р. Э., Здоровеннова Г. Э. Особенности термической структуры мелководного озера в начале зимы // Водные ресурсы. 2006. Т. 33, № 2. С. 154-162.

Петров М. П., Тержевик А. Ю., Здоровеннов Р. Э., Здоровеннова Г. Э. Движения воды в мелководном озере, покрытом льдом // Водные ресурсы. 2007. T. 34, № 2. C. 131-140.

Bengtsson L., Svensson T. Thermal regime of icecovered Swedish lakes // Nordic Hydrol. 1996. Vol. 27. P. 39-56.

Golosov S., Zverev I., Terzhevik A. Modelling thermal structure and heat interaction between water column and bottom sediments in ice-covered lakes // Proc. $7^{\text {th }}$ Workshop on Physical Processes in Natural Waters, A. Terzhevik (ed.). Petrozavodsk. 2003. P. 83-88.

Kirillin G., Engelhardt C., Golosov S., Hintze T. Basin-scale internal waves in the bottom boundary layer of ice-covered Lake Muggelsee, Germany // Aquat Ecol. 2009. Vol. 43, no. 3. P. 641-651. doi:10.1007/ s10452-009-9274-3

Kirillin G., Leppäranta M., Terzhevik A. et al. Physics of seasonally ice-covered lakes: a review // Aquatic Sciences. 2012. 74 (4). P. 659-682.

Malm J. Bottom buoyancy layer in an ice-covered lakes // Water Resources Research. 1998. Vol. 34, no. 11. P. 2981-2993.

Malm J., Terzhevik A., Bengtsson L. et al. Temperature and Hydrodynamics in Lake Vendurskoe during Winter 1995/1996. Department of Water Resources Engineering, Institute of Technology. University of Lund, 1997. No. 3213. 203 p.

Mortimer C. H., Mackereth F. J. H. Convection and its consequences in ice-covered lakes // Int. Ver. Theor. Angew. Limnol. Verh. 1958. No. 13. P. 923-932.

Rizk W., Kirillin G., Leppäranta M. Basin-scale circulation and heat fluxes in ice-covered lakes // Limnol. Oceanogr. 2014. 59 (2). P. 445-464.

Zdorovennova G. E. Spatial and temporal variations of the water-sediment thermal structure in shallow ice-covered Lake Vendyurskoe (Northwestern Russia) // Aquatic Ecology. 2009. Vol. 43. P. 629-639. doi: 10.1007/s10452-009-9277-0

Поступила в редакцию 17.02.2016 


\section{References}

Boyarinov P. M., Petrov M. P. Protsessyi formirovaniya termicheskogo rezhima glubokih presnovodnyih vodoemov [Formation processes of thermal regime in deep freshwater bodies]. Leningrad: Nauka, 1991. 175 p.

Gavrilenko G. G., Zdorovennova G. E., Zdorovennov R. E., Palshin N. I., Mitrohov A. V., Terzhevik A. Yu. Teplopotok na granice voda-donnye otlozheniya $v$ nebolshom ozere [Heat flux at the water-sediment interface in a shallow lake]. Trudy KarNC RAN [Trans. KarRC RAS]. 2015. No. 9. P. 3-9.

Zdorovennov R. E., Zdorovennova G. E., Palshin N. I., Terzhevik A. Yu. Izmenchivost termicheskogo I kislorodnogo rezhimov melkovodnogo ozera zimoj [Variation of the temperature and oxygen regimes of a shallow lake in winter]. Trudy KarNC RAN [Trans. KarRC RAS]. 2011. No. 4. P. 57-63.

Litinskaya K. D., Polyakov Yu. K. Ozera Vendyursko] gruppy - Uros, Rindozero, Vendyurskoe [Lakes of Vendyury group - Uros, Rindozero and Vendyurskoe]. In: Vodnye resursy karelii I ih ispolzovanie [Water resources of Karelia and their use]. Petrozavodsk: Karelskij filial AN SSSR, 1975. P. 57-66.

Patent RF № 153787. 7.07.2015.

Petrov M. P., Terzhevik A. Yu., Zdorovennov R. E., Zdorovennova G. E. Osobennosti termicheskoj struktury melkovodnogo ozera $v$ nachale zimy [The thermal structure of a shallow lake in early winter]. Vodnye resursy [Water resources]. 2006. Vol. 33, no. 2. P. 154-162.

Petrov M. P., Terzhevik A. Yu., Zdorovennov R. E., Zdorovennova $G$. E. Dvizheniya vody $v$ melkovodnom ozere pokrytom Idom [Motion of water in an ice-covered shallow lake]. Vodnye resursy [Water resources]. 2007. Vol. 34, no. 2. P. 131-140.

Bengtsson L., Svensson T. Thermal regime of icecovered Swedish lakes. Nordic Hydrol. 1996. Vol. 27. P. 39-56.

\section{СВЕДЕНИЯ ОБ АВТОРАХ:}

\author{
Здоровеннова Галина Эдуардовна \\ и. о. зав. лабораторией гидрофизики, к. г. н. \\ Институт водных проблем Севера \\ Карельского научного центра РАН \\ пр. А. Невского, 50, Петрозаводск, Республика Карелия \\ Россия, 185030 \\ эл. почта: zdorovennova@gmail.com \\ тел.: 89116660369
}

\section{Здоровеннов Роман Эдуардович}

старший научный сотрудник лаборатории гидрофизики,

к. г.н.

Институт водных проблем Севера

Карельского научного центра РАН

пр. А. Невского, 50, Петрозаводск, Республика Карелия,

Россия, 185030

эл. почта: romga74@gmail.com

тел.: 89212209438
Golosov S., Zverev I., Terzhevik A. Modelling thermal structure and heat interaction between water column and bottom sediments in ice-covered lakes. Proc. $7^{\text {th }}$ Workshop on Physical Processes in Natural Waters, A. Terzhevik (ed.). Petrozavodsk. 2003. P. 83-88.

Kirillin G., Engelhardt C., Golosov S., Hintze T. Basin-scale internal waves in the bottom boundary layer of ice-covered Lake Muggelsee, Germany. Aquat. Ecol. 2009. Vol. 43, no. 3. P. 641-651. doi: 10.1007/ s10452-009-9274-3

Kirillin G., Leppäranta M., Terzhevik A., Granin N., Bernhardt J., Engelhardt C., Efremova T., Golosov S., Palshin N., Sherstyankin P., Zdorovennova G., Zdorovennov $R$. Physics of seasonally ice-covered lakes: a review. Aquatic Sciences. 2012. 74 (4). P. 659-682.

Malm J. Bottom buoyancy layer in an ice-covered lakes. Water Resources Research. 1998. Vol. 34, no. 11 P. 2981-2993.

Malm J., Terzhevik A., Bengtsson L., Boyarinov P., Glinsky A., Palshin N., Petrov M. Temperature and Hydrodynamics in Lake Vendurskoe during Winter 1995/1996. Department of Water Resources Engineering, Institute of Technology. University of Lund, 1997. No. 3213. 203 p.

Mortimer C. H., Mackereth F. J. H. Convection and its consequences in ice-covered lakes. Int. Ver. Theor. Angew. Limnol. Verh. 1958. No. 13. P. 923-932.

Rizk W., Kirillin G., Leppäranta M. Basin-scale circulation and heat fluxes in ice-covered lakes. Limnol. Oceanogr. 2014. 59 (2). P. 445-464.

Zdorovennova G. E. Spatial and temporal variations of the water-sediment thermal structure in shallow ice-covered Lake Vendyurskoe (Northwestern Russia). Aquatic Ecology. 2009. Vol. 43. P. 629-639. doi: 10.1007/s10452-009-9277-0

Received February 17, 2016

\section{CONTRIBUTORS:}

\section{Zdorovennova, Galina}

Northern Water Problems Institute, Karelian Research Centre, Russian Academy of Sciences

50 A. Nevsky St., 185030 Petrozavodsk, Karelia, Russia e-mail: zdorovennova@gmail.com tel.: 89116660369

\section{Zdorovennov, Roman}

Northern Water Problems Institute, Karelian Research Centre, Russian Academy of Sciences 50 A. Nevsky St., 185030 Petrozavodsk, Karelia, Russia e-mail: romga74@gmail.com tel.: 89212209438 
Пальшин Николай Иннокентьевич

старший научный сотрудник лаборатории гидрофизики, К. Г. Н.

Институт водных проблем Севера

Карельского научного центра РАН

пр. А. Невского, 50, Петрозаводск, Республика Карелия, Россия, 185030

эл. почта: npalshin@mail.ru

\section{Ефремова Татьяна Владимировна}

старший научный сотрудник лаборатории гидрофизики, к. г. н.

Институт водных проблем Севера

Карельского научного центра РАН

пр. А. Невского, 50, Петрозаводск, Республика Карелия, Россия, 185030

эл. почта: efremova@nwpi.krc.karelia.ru

\section{Гавриленко Галина Геннадиевна}

младший научный сотрудник лаборатории гидрофизики Институт водных проблем Севера

Карельского научного центра РАН

пр. А. Невского, 50, Петрозаводск, Республика Карелия, Россия, 185030

эл. почта: south.sun.cr@gmail.com

тел.: 89602115561

\section{Богданов Сергей Рэмович}

ведущий научный сотрудник лаборатории гидрофизики, д. Ф.-М. н.

Институт водных проблем Севера

Карельского научного центра РАН

пр. А. Невского, 50, Петрозаводск, Республика Карелия,

Россия, 185030

эл. почта: sergey.r.bogdanov@mail.ru

\section{Тержевик Аркадий Юрьевич}

ведущий научный сотрудник лаборатории гидрофизики,

К. Т. н.

Институт водных проблем Севера

Карельского научного центра РАН

пр. А. Невского, 50, Петрозаводск, Республика Карелия,

Россия, 185030

эл. почта: ark1948@list.ru
Palshin, Nikolai

Northern Water Problems Institute, Karelian Research Centre, Russian Academy of Sciences

50 A. Nevsky St., 185030 Petrozavodsk, Karelia, Russia

e-mail: npalshin@mail.ru

\section{Efremova, Tatyana}

Northern Water Problems Institute, Karelian Research Centre, Russian Academy of Sciences

50 A. Nevsky St., 185030 Petrozavodsk, Karelia, Russia

e-mail: efremova@nwpi.krc.karelia.ru

\section{Gavrilenko, Galina}

Northern Water Problems Institute, Karelian Research Centre, Russian Academy of Sciences

50 A. Nevsky St., 185030 Petrozavodsk, Karelia, Russia e-mail: south.sun.cr@gmail.com

tel.: 89602115561

\section{Bogdanov, Sergey}

Northern Water Problems Institute, Karelian Research Centre, Russian Academy of Sciences

50 A. Nevsky St., 185030 Petrozavodsk, Karelia, Russia

e-mail: sergey.r.bogdanov@mail.ru

\section{Terzhevik, Arkady}

Northern Water Problems Institute, Karelian Research Centre,

Russian Academy of Sciences

50 A. Nevsky St., 185030 Petrozavodsk, Karelia, Russia

e-mail: ark1948@list.ru 